\title{
Lack of Evidence for Transmission of 'Candidatus Liberibacter asiaticus' Through Citrus Seed Taken from Affected Fruit
}

John S. Hartung, United States Department of Agriculture, Agricultural Research Service, Molecular Plant Pathology Laboratory, Beltsville, MD 20705; Susan E. Halbert, Florida Department of Agriculture and Consumer Services, Division of Plant Industry, Gainesville, FL 32608; and Kirsten Pelz-Stelinski, Ronald H. Brlansky, Chunxian Chen, and Fred G. Gmitter, University of Florida, Citrus Research and Education Center, Lake Alfred, FL 33850

\begin{abstract}
Hartung, J. S., Halbert, S. E., Pelz-Stelinski, K., Brlansky, R. H., Chen, C., and Gmitter, F. G. 2010. Lack of evidence for transmission of 'Candidatus Liberibacter asiaticus' through citrus seed taken from affected fruit. Plant Dis. 94:1200-1205.

Citrus huanglongbing, putatively caused by the associated bacterium 'Candidatus Liberibacter asiaticus', is the greatest threat to the world citrus industry today. The bacterium is spread locally and regionally by the citrus psyllid Diaphorina citri, and also can be disseminated by propagation of contaminated scion budwood that is grafted to the appropriate rootstock. The planting of ' $\mathrm{Ca}$. Liberibacter asiaticus'-free trees is a component of a comprehensive strategy to manage huanglongbing. In contrast to the scion budwood, the rootstocks used to produce these trees are grown from seed. This research was undertaken to provide evidence as to whether or not ' $\mathrm{Ca}$. $\mathrm{L}$. asiaticus' can be transmitted through seed. Two groups of 360 or more seedlings each of various citrus species were grown from seed removed from fruit on trees that were symptomatic for huanglongbing and confirmed to be infected with ' $\mathrm{Ca}$. L. asiaticus' by polymerase chain reaction (PCR) tests. These seedlings were tested multiple times over periods of up to 3 years. No symptoms typical of huanglongbing, such as blotchy leaf mottle, chlorotic shoots, or dieback of branches, were observed in these seedlings, and none of these 723 seedlings tested positive for the presence of ' $\mathrm{Ca}$. L. asiaticus' even after repeated testing by sensitive quantitative PCR assays. Some sour orange seedlings did have quite pronounced and atypical growth, including stunting and mild to severe leaf malformation. These atypical growth habits were limited to seedlings that arose from zygotic embryos as determined by expressed-sequence tag simplesequence repeat analyses. Thus, no evidence of transmission of ' $\mathrm{C} a$. L. asiaticus' via seed was obtained, and an earlier report of transmission of the pathogen through seed was not confirmed.
\end{abstract}

Huanglongbing (HLB), greening, vein phloem degeneration, and yellow shoot are different names for the most serious disease of citrus (4). HLB is the accepted name of the disease (9). The disease was described first from India early in the 20th century (20). There is no published account of HLB in China until 1956, although the disease is now widespread in that country $(4,30)$. During the 20th century, the disease was reported throughout southeast Asia and the regions bordering the Indian Ocean basin as well as in southern and eastern Africa. HLB was not known to be present in the Western Hemisphere until it was reported to be widespread in Brazil (36) and Florida (13) in 2004 and 2005, respectively.

Corresponding author: J. S. Hartung

E-mail: John.Hartung@ars.usda.gov

Accepted for publication 16 June 2010.

doi:10.1094/PDIS-09-09-0595

This article is in the public domain and not copyrightable. It may be freely reprinted with customary crediting of the source. The American Phytopathological Society, 2010.
Symptoms (17) of the disease include a distinctive mottle on fully expanded leaves. Leaves with mottle develop on shoots that are irregularly distributed in the diseased tree as the shoots mature. Infected shoots also are stunted and gradually die as the symptoms appear in other sectors of the tree. Fruit from affected branches can be lopsided, with a color inversion as the fruit ripens, remaining green at the stylar end of the fruit. Yield is reduced directly by fruit drop and indirectly by gradual tree decline and death. Juice produced from fruit from affected trees is of low quality, being similar to juice from immature fruit (10). Affected trees can produce fruit which can contain aborted seed $(4,35)$, suggesting that seed can become contaminated with the putative pathogen, and there is a previous preliminary report of transmission of the pathogen through seed taken from affected fruit (39). Symptoms of the disease are strongly associated by both electron microscopy (15) and polymerase chain reaction (PCR)-based assays $(22,31)$ and, most recently, by metagenomic analysis (40) with the presence of bacteria in the phloem of infected trees. In spite of numerous attempts $(11,14,16,33)$, the bacterium is not available in culture and, hence, Koch's postulates have not been formally completed. Although symptoms of the disease in Asia, North and South America, and southern Africa are similar, analysis of the $16 \mathrm{~S}$ ribosomal RNA gene of the HLB-associated bacteria from these regions has led to the recognition of three species of the 'Candidatus' genus Liberibacter: 'Candidatus Liberibacter asiaticus', ' $\mathrm{Ca}$. Liberibacter africanus', and ' $C a$. L. americanus' $(22,37)$. These three ' $\mathrm{Ca}$. Liberibacter spp.' are members of the $\alpha$-subdivision of the phylum Proteobacteria (21) and are the putative pathogens associated with HLB. The recently published full-genome sequence places ' $C a$. L. asiaticus' within the family Rhizobiaceae, though with a greatly reduced genome compared with other members of that family $(12,40)$.

Our knowledge of modes of transmission within ' $\mathrm{Ca}$. Liberibacter' is incomplete. ' $C a$. L. africanus' has been shown to be transmitted vertically through the eggs of its insect vector, Trioza erytreae (41). In addition, ' $\mathrm{Ca}$. L. psyllaurous' (syn. ' $\mathrm{Ca}$. L. solanacearum'), a putative pathogen of potato associated with a yellows disorder, has been reported to be vertically transmitted through the eggs of the psyllid vector Bactericera cockerelli (Sulc) (18). In addition to the disease in potato, ' $\mathrm{Ca}$. L. solanacearum' has been associated with a similar and serious disease of greenhouse tomato following the introduction of $B$. cockerelli into New Zealand and with the zebra chip disease of potato tubers in the United States $(28,29,34)$. Transmission of ' $C a$. L. asiaticus' through infected citrus seed has been reported (39) based on the rapid appearance of HLB-like symptoms in seedlings when apparently healthy seed harvested from symptomatic fruit were planted. ' $C a$. L. asiaticus' was also readily detected throughout HLB-affected fruit by quantitative qPCR $(26,35)$ and in the seed coat but not the embryos of limited numbers of seed collected from HLB-affected fruit (35).

In view of the above, the purpose of this work was to provide evidence for or against the hypothesis that ' $\mathrm{Ca}$. L. asiaticus' can be transmitted vertically through seed to seedlings. This information is cru- 
cial to management of HLB disease. The planting of ' $\mathrm{Ca}$. L. asiaticus'-free trees is a critical component of a comprehensive strategy to manage HLB. Millions of ' $\mathrm{Ca}$. L. asiaticus'-free trees are produced annually after propagation from bud sources tested for the presence of the pathogen. These trees are grown under screen to shield them from citrus psyllids to assure that, when planted, they are free of ' $\mathrm{Ca}$. L. asiaticus.' In contrast to the scion budwood, the rootstocks used to produce these trees are grown from seed, obtained from fruit produced on trees that are not protected from the citrus psyllids. Thus, if the trees used to obtain seed for use as rootstocks were infected with ' $\mathrm{Ca}$. L. asiaticus', and if the pathogen could be transmitted through seed, the effort to control HLB disease would be compromised. Also, citrus germplasm is often exchanged as seed and, thus, a pathway for the potential introduction of HLB into previously HLB-free regions would exist.

\section{MATERIALS AND METHODS}

Seed and seedlings-Lake Alfred. A set of 360 sweet orange (Citrus sinensis (L.) Osbeck) seed was collected from fruit harvested from HLB-symptomatic and qPCR-positive trees for an unrelated juice quality study (10). The cycle threshold (Ct) values determined by qPCR for the trees from which the fruit was harvested, assayed from leaf midribs (26), were always below 32 and generally were between 25 and 28. Fruit harvested from the symptomatic and qPCR-positive trees were divided into groups (Table 1) depending on the symptoms visible on the fruit, either asymptomatic (group I) or symptomatic (group II; Fig. 1). Seed from a third set of fruit from the same source trees but for which disease symptoms were not evaluated were also tested (group III; fruit symptoms undetermined). An additional 90 seeds were collected from fruit produced by healthy-appearing and qPCRnegative sweet orange trees (group IV, negative controls). All seed were sown, including discolored or shriveled seed, between December 2007 and February 2008 in Cone-tainer cells (Stuewe \& Sons, Inc., Tangent, OR) containing Fafard potting mix (Conrad Fafard, Inc., Agawam, MA). Plants were fertilized every 2 weeks with a liquid fertilizer containing nitrogen:potassium:phosphorus at a ratio of 20:10:20 (J. R. Peter's, Allentown, PA). The seedlings were grown in a certified psyllid-free greenhouse and were observed regularly for blotchy leaf mottle, stunting, and chlorosis, the typical symptoms of HLB.

Seed and seedlings-Beltsville. Fruit showing clear symptoms of HLB (Fig. 2) were collected from HLB-diseased trees identified in the course of disease surveys carried out by the Florida Department of Agriculture and Consumer Services, De- partment of Plant Industry (DPI). Samples from the trees and branches bearing the fruit tested positive for the presence of ' $\mathrm{Ca}$. L. asiaticus' by PCR and gel electrophoresis (22). The identity of some of the amplicons was confirmed as ' $\mathrm{Ca}$. L. asiaticus' by DNA sequencing. This testing was done at the Advanced Diagnostic Laboratory, DPI, Gainesville, FL. Seed were removed from these fruit and shipped under phytosanitary permit to Beltsville, MD, between December 2005 and February 2006. The host and location of origin as well as the general condition of the seed were recorded. All seed were planted, including discolored or shriveled seed. The citrus and related plants tested included rough lemon (C. jambhiri Lush), sour orange $(C$. aurantium L.), grapefruit $(C$. paradisi Macf.), tangerine (C. reticulata), 'Meyer' lemon (Citrus $\times$ limon L. Burm. f.), Valencia sweet orange (C. sinensis (L.)), and Murraya paniculata. Plants were grown in Metro-Mix 510 (Sun Gro Horticulture, Bellevue, WA) and fertilized by irrigation with nitrogen:phosphorus: potassium (21:5:19) with nitrogen at 100 ppm. Copper and iron were added to 2 and $6 \mathrm{ppm}$, respectively. Ambient light was supplemented with $4 \mathrm{~h}$ of high-pressure sodium lighting in the winter months. The greenhouse is very well screened and the citrus psyllid has never been detected in Maryland. The set of 363 seedlings that emerged was observed regularly for visual symptoms of HLB or other abnormalities and tested for ' $\mathrm{Ca}$. L. asiaticus' by qPCR.

Testing of seedlings for ' $\mathrm{Ca}$. $\mathrm{L}$. asiaticus' by qPCR. Seedlings were tested for the presence of ' $C a$. L. asiaticus' at 6 to 8 , 18,25 , and 35 months after sowing (Beltsville) or at 7 to 10 months (Lake Alfred). Three fully expanded leaves were removed from each seedling. Midribs from the three leaves were separated from the leaf blade and pooled and minced with a razor blade. Chopped midribs (200 mg) constituted a sample. Total DNA from each sample was isolated using a FastPrep bead mill (MP Biomedical, Solon, $\mathrm{OH}$ ) and stainless steel beads and a slightly modified DNeasybased procedure (Qiagen, Germantown,

Table 1. Summary of test results (Lake Alfred) for possible transmission of 'Candidatus Liberibacter asiaticus' through sweet orange seed ${ }^{\text {a }}$

\begin{tabular}{lccccccc}
\hline & \multicolumn{2}{c}{ Source tree status $^{\mathbf{b}}$} & & Fruit status & & \multicolumn{2}{c}{ Seedling status } \\
\cline { 2 - 3 } \cline { 7 - 7 } \cline { 7 - 7 } Group & HLB symptoms $^{\mathbf{c}}$ & $\mathbf{q P C R}^{\mathbf{d}}$ & & HLB symptoms & & qPCR+ & HLB symptoms \\
\hline I & $152 / 152$ & $152 / 152$ & & $0 / 152$ & & $0 / 152$ & $0 / 152$ \\
II & $113 / 113$ & $113 / 113$ & & $113 / 113$ & & $0 / 113$ & $0 / 113$ \\
III & $95 / 95$ & $95 / 95$ & & Undetermined & & $0 / 95$ & $0 / 95$ \\
IV & $0 / 90$ & $0 / 90$ & & $0 / 90$ & & $0 / 90$ & $0 / 90$ \\
\hline
\end{tabular}

a Tests carried out from December 2007 through September 2008.

b Seedlings grouped based on external symptoms on source trees and fruit and the results of quantitative polymerase chain reaction (qPCR) testing of source trees and seedlings for ' $\mathrm{Ca}$. L. asiaticus'. Cycle threshold values for source tree samples (midribs) generally ranged from 25 to 28 with a high value of 32 . Forty cycles of amplification were used.

${ }^{c} \mathrm{HLB}=$ huanglongbing.

${ }^{\mathrm{d}}$ Number of positive reactions/number of samples tested. Reactions were considered negative if no product was detected after 40 cycles of amplification or positive if a product appeared in less than 40 cycles. 
two sets. Some DNA samples were included in both sample sets as controls for consistency of scoring. Marker genotype shifts from heterozygous to homozygous at one or more loci are indicative of a zygotic embryo originating from self-pollination. In other words, seedlings with aa or bb genotype produced by their parent with $a b$ genotype (heterozygous locus) must be zygotic whereas seedlings with ab at the locus are either zygotic or nucellar. Unique alleles are indicative of a zygotic embryo arising from out-crossing.

\section{RESULTS}

Lake Alfred. None of the 360 seedlings produced from seed obtained from fruit borne on HLB-symptomatic and qPCR-positive trees displayed symptoms of HLB, and qPCR assays did not detect ' $\mathrm{Ca}$. L. asiaticus' in these seedlings after 40 cycles of amplification. Likewise, none of the 90 seedlings produced from HLB symptom-free fruit from healthy trees had symptoms of HLB, and qPCR assays did not detect ' $\mathrm{Ca}$. L. asiaticus' in these seedlings (Table 1).

Beltsville. In total, 363 seedlings were grown for analysis (Table 2). These seedlings were tested four times over a period of 3 years while growing in an insect-proof greenhouse. In total, 1,216 DNA extractions and assays were completed. In no case was any amplification of ' $\mathrm{Ca}$. L. asiaticus' sequence obtained from extracts of the tested seedlings with 40 amplification cycles, although the positive control samples provided $\mathrm{Ct}$ values of 20 to 23 .

Ten of the sour orange seedlings developed atypically (Fig. 3) but none of these seedlings tested positive for ' $\mathrm{Ca}$. L. asiaticus' by qPCR. Atypical development included stunting, with or without mild to severe leaf malformation or a tendency for excessive branching. Yellow shoots, blotchy mottle, and progressive chlorosis leading to shoot dieback (symptoms typical of HLB) were not observed. Because of the atypical development observed in some of the seedlings, a final set of extractions from 61 surviving sour orange seedlings (typical and atypical) was made 42 months after sowing. These included two sets of samples from midribs and three sets of samples from the roots. In these tests, the mean $\mathrm{Ct}$ value of the positive control for ' $\mathrm{Ca}$. L. asiaticus' included in each set of reactions was 20.3 and the mean value of the COX assay in the positive control tubes was 19.5. The mean value of the COX assays of the test samples themselves was 18.9. None of these extracts tested positive for ' $\mathrm{Ca}$. L. asiaticus' after 40 cycles of amplification.

Because the atypical development observed in several of the sour orange seedlings could not be associated with ' $\mathrm{Ca}$. L. asiaticus', the hypothesis that the atypical seedlings were the result of zygotic embryogenesis was tested. Such seedlings are routinely found from certain crosses made in breeding programs and may also occur in populations of rootstock seedlings in citrus-production nurseries where they would routinely be destroyed. Therefore, the genotypes of all 10 of the atypical seedlings and 13 normal seedlings were tested with up to 24 unique EST-SSR loci to distinguish definitively the zygotic from nucellar seedlings. Zygotics were distinguished by segregation from heterozygous to homozygous at one or more loci. No unique alleles were found, indicating that all of the zygotic seedlings were most likely the result of self-fecundation. In comparing the dataset generated on seedling embryo origins with the phenotypes of the seedlings used to extract DNA, all of the plants exhibiting atypical development (Fig. 3) were shown to be zygotic, and all of the plants with typical development had marker genotypes expected for nucellar sour orange seedlings (Table 3). DNA extracts present in both sample sets provided identical results.

\section{DISCUSSION}

There are other vascular pathogens of citrus with disease epidemiologies similar in many respects to ' $\mathrm{Ca}$. L. asiaticus' and HLB. These include Xylella fastidiosa, a member of the $\gamma$-subdivision of the phylum Proteobacteria. This pathogen lives in the xylem vessels of sweet orange trees and causes a serious disease in South America called citrus variegated chlorosis $(5,19)$.

Table 2. Summary of test results (Beltsville) for possible transmission of 'Candidatus Liberibacter asiaticus' through seed ${ }^{\mathrm{a}}$

\begin{tabular}{|c|c|c|c|c|c|}
\hline \multirow[b]{2}{*}{ Source $^{c}$} & \multicolumn{5}{|c|}{ Time (months) between sowing of seed and DNA extraction and testingb } \\
\hline & Seedlings & 6 to 8 & 20 & 25 & 35 \\
\hline Murraya & 11 & $0 / 2$ & $0 / 1$ & $0 / 8$ & Dead \\
\hline Rough lemon & 106 & $0 / 106$ & nd & $0 / 101$ & 0/99 \\
\hline Sour orange & 84 & $0 / 79$ & $0 / 84$ & $0 / 81$ & $0 / 82$ \\
\hline Grapefruit & 15 & $0 / 14$ & $0 / 3$ & $0 / 14$ & $0 / 15$ \\
\hline Tangerine & 18 & nd & $0 / 17$ & $0 / 18$ & $0 / 17$ \\
\hline Meyer lemon & 20 & $0 / 19$ & $0 / 20$ & $0 / 19$ & $0 / 18$ \\
\hline Valencia & 109 & $0 / 106$ & $0 / 83$ & $0 / 106$ & $0 / 104$ \\
\hline Total $^{\mathrm{d}}$ & 363 & 326 & 208 & 347 & 335 \\
\hline
\end{tabular}

a Tests carried out from January 2006 through December 2008. Grand total of tests completed = 1,216

b Number of positive quantitative polymerase chain reaction (qPCR) tests/number of tests completed. Reactions were considered negative if no product was detected after 40 cycles of amplification. Dead $=$ tests not done on this date because trees had died of root rot; nd $=$ plants not tested this date by omission.

c All source trees were highly symptomatic and the presence of ' $\mathrm{Ca}$. L. asiaticus' was confirmed by PCR (22) prior to tree removal by Florida Department of Agriculture and Consumer Services, Department of Plant Industry and collection of fruit for testing.

$\mathrm{d}$ Total number of seedlings and tests completed by each date.

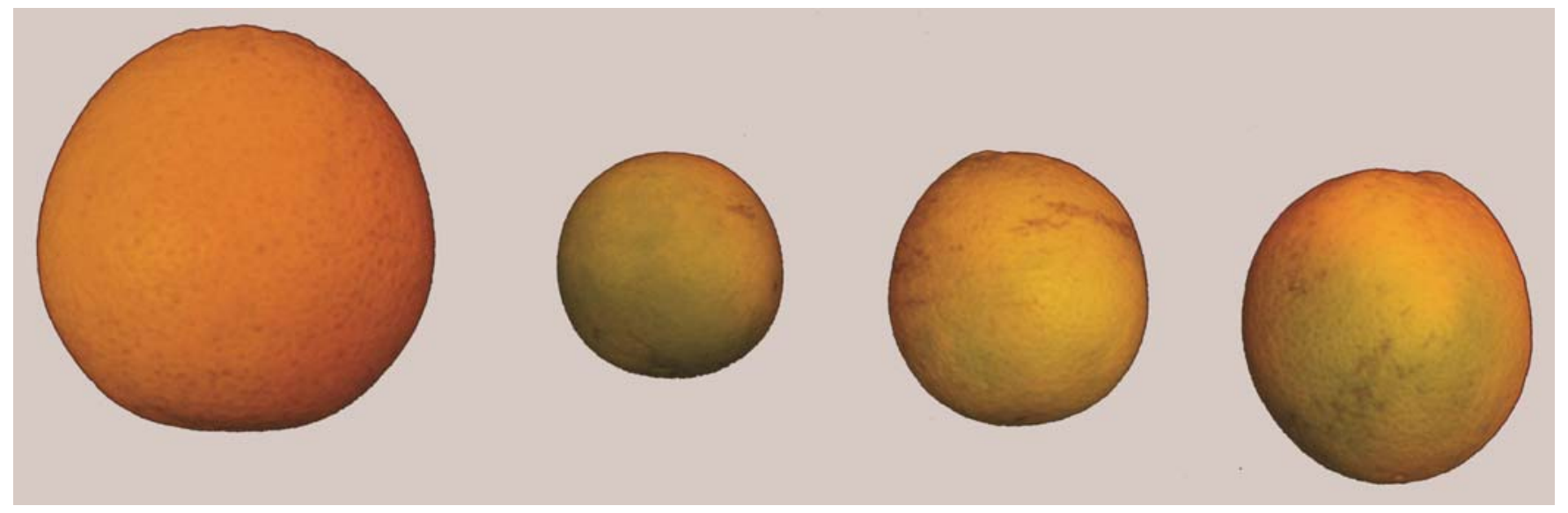

Fig. 1. External symptoms of huanglongbing on fruit harvested to extract seed for seedling tests. Sweet orange with normal appearance on the left, with three fruit showing varying degrees of atypical coloration, failure to size properly, and aymetrical development on the right. 
Spiroplasma citri, a mollicute, lives in the phloem vessels of infected citrus and causes citrus stubborn disease in California and the Mediterranean basin, where it is transmitted by the leafhoppers, Circulifer tenellus (Baker) and Scaphytopius nitridus (DeLong). Two different phytoplasmas have recently been associated with disease symptoms in sweet orange that are very difficult to distinguish from HLB. In São Paulo, Brazil, a member of the pigeon pea witches'-broom group (16Sr IX) causes symptoms very similar to HLB over a wide area but at low incidence. In these plants, ' $C a$. L. asiaticus' could not be found, and the pathogen was thought to be transmitted by insects from surrounding vegetation (38). In Guangdong, China, a member of

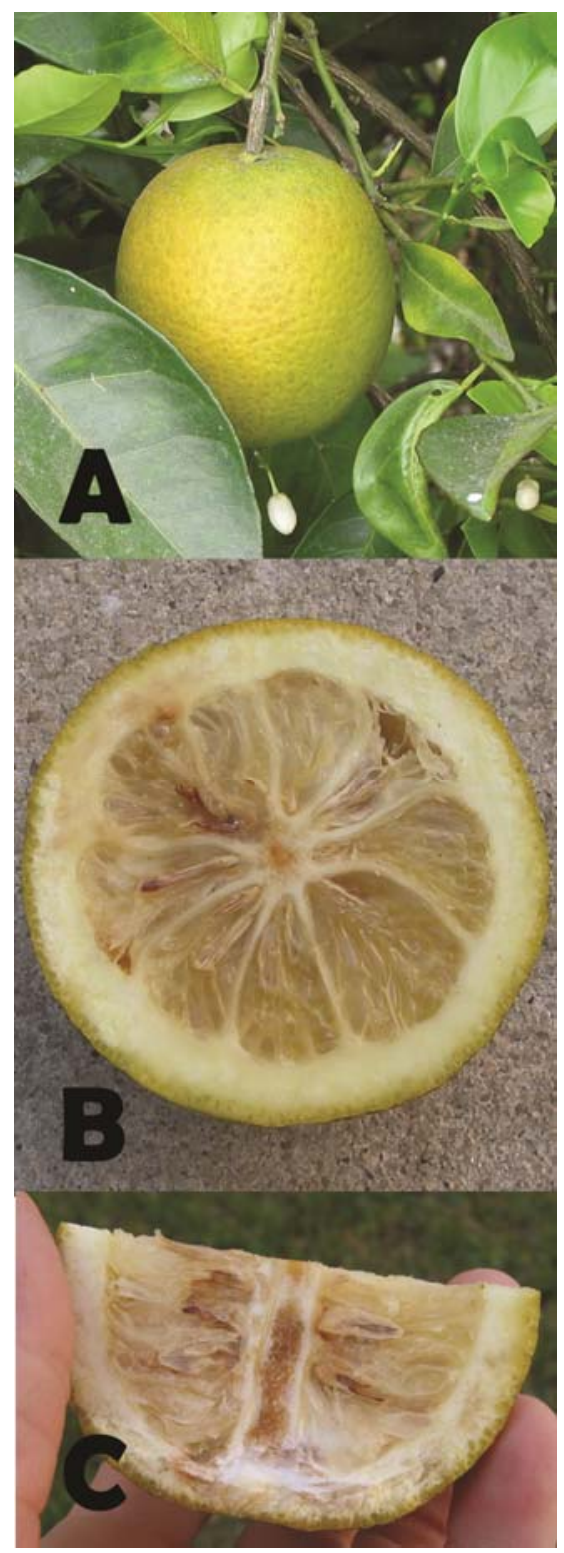

Fig. 2. A, Huanglongbing (HLB)-symptomatic fruit is shown on the tree. Internal symptoms of HLB in sweet orange fruit harvested to extract seed for seedling tests in $\mathbf{B}$, cross-section showing aborted and discolored seed and $\mathbf{C}$, longitudinal section showing prominent discoloration of the columnella and seed. the aster yellows group (16Sr I-B) of phytoplasmas has also been detected in suspected HLB-diseased plants by PCR. In this study, co-infection of plants with both ' $\mathrm{Ca}$. L. asiaticus' and ' $\mathrm{Ca}$. Phytoplasma asteris' was observed more frequently in samples than was either pathogen alone (8). There is no information available on transmission through seed of these phytoplasma. S. citri and X. fastidiosa are both known to heavily infect the seed coat of infected sweet orange $(3,27)$. X. fastidiosa also has been reported to be vertically transmitted through infected seed (27). We are not aware of published work on whether or not S. citri is transmitted through sweet orange seed; however, this was tested in California with negative results, which were not published (I.-M. Lee, personal communication). Citrus seed often are aborted in HLB-symptomatic fruit $(4,17$; Fig. 2), suggesting that the HLB-associated pathogen is able to reach the seed. 'Ca. L. asiaticus' has been detected in portions of citrus fruit, including the peduncle and columella $(26,35)$ as well as in the seed coat, but not in the combined endosperm and embryo tissues, although a faint band attributed to contamination from the seed coat was observed when the latter extract was assayed (35). In order to be transmitted to seedlings, the pathogen would have to pass from the vascular system present in the seed coat through the chalazal cup, a permeable layer of cells that separates the embryo from the vascular system of the mother plant (32). Water and all nutrients necessary to support the development of the embryos pass through this layer of cells. The pathogen would then have to locate and enter the phloem cells, which are not visibly differentiated in sweet orange seed (32). How this would be accomplished is completely unknown and beyond the scope of this study.

We reasoned that, if ' $\mathrm{Ca}$. L. asiaticus' were transmitted through seed, transmission would most likely occur from fruit showing symptoms of the disease (lopsidedness, color inversion, and bitter juice) produced on trees with HLB symptoms. We also reasoned that infected seedlings should show symptoms of HLB, as reported earlier (39). Because HLB symptoms can be confusing and nonspecific, HLB diagnosis should be confirmed by qPCR (24). This confirmation was not available for the earlier study. Fruit of several varieties fitting this description were readily available in Florida and were collected from HLB-affected trees for use in the Beltsville study. Sweet orange fruit, collected separately with similar criteria for a juice quality study (10), were also tested for transmission of ' $\mathrm{Ca}$. L. asiaticus' through seed.

Seed were germinated and grown under greenhouse conditions. Leaf samples were collected and DNA extractions and qPCR tests were completed using standard methods $(23,24)$. Tests in Florida were limited to one test at 7 to 10 months after sowing of the seed. No HLB symptoms were observed and no positive qPCR results were obtained from the 360 seedlings tested in Florida. Some of these seedlings have been maintained to date and remain free of HLB symptoms. In the Beltsville study, which included seven varieties of citrus plus $M$. paniculata, no symptoms of HLB were observed and no positive qPCR tests were obtained at 6 to 8 months after sowing. We reasoned that, although initial tests were negative, ' $C a$. L. asiaticus' may be slow to establish in seedlings and populations might increase over time, leading to the production of both symptoms of HLB and

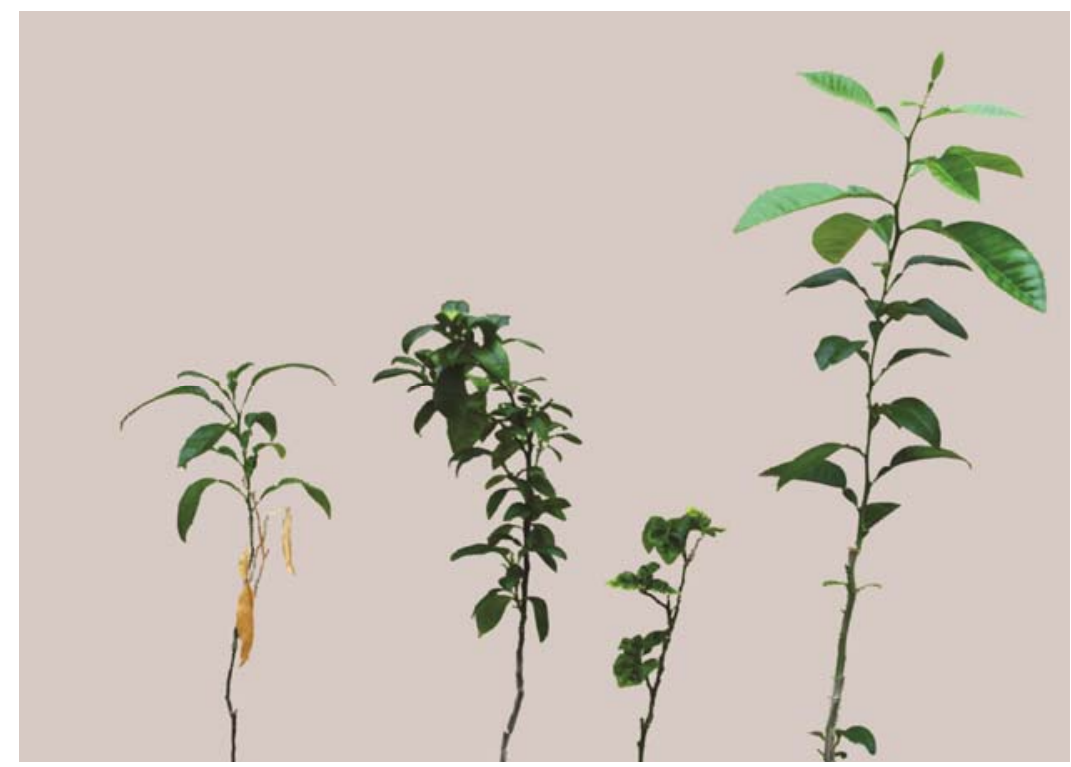

Fig. 3. From the left, sour orange seedlings S389, S433, and S391, respectively, showing atypical growth habits, including stunting, stunting with phyllody, and severe stunting and leaf malformation. A typical sour orange seedling of the same age is shown on the right for comparison. 
detection of the putative pathogen by qPCR. Therefore, seedlings were grown for 3 years; however, no symptoms of HLB or positive qPCR results were oblings. These tests were done on midribs removed from fully matured leaves, a tissue which has been shown to have the highest titer of ' $\mathrm{Ca}$. L. asiaticus' in infected trees (26).

In the course of these studies, although blotchy leaf mottle symptoms typical of HLB were never observed in any seedling, several of the sour orange seedlings developed atypically. These developmental abnormalities included mild to severe stunting, increased branching, and mild to severe leaf distortions. All of the testing to this point had been done with leaf midribs but ' $\mathrm{Ca}$. L. asiaticus' has been shown to colonize roots as well as above ground tissues of trees (26). We considered the possibility that ' $\mathrm{Ca}$. L. asiaticus' preferentially colonized seedling root tissues. Therefore, as a final test, samples from roots and midribs of 61 sour orange seedlings were tested by qPCR. All of these served in these further tests of the seed-

tests were also negative for ' $\mathrm{Ca}$. L. asiaticus' after 40 cycles. All of the qPCR tests conducted at Lake Alfred and Beltsville included a plant DNA control (cytochrome oxidase) target to confirm template DNA quality, and each set of reactions contained a positive control for ' $\mathrm{Ca}$. L. asiaticus'. Thus, these results are reliably and conclusively negative for the presence of ' $\mathrm{Ca}$. L. asiaticus' in these seedlings.

We wished to provide an explanation for the atypical development of several of the sour orange seedlings grown from seed produced by HLB symptomatic fruit. DNA from the sour orange seedlings was tested further to determine whether the atypical development observed in some of the seedlings was related to a possible zygotic origin and consequent genetic recombination to yield seedlings with unusual phenotypic characteristics. Although the parental genotypes of these field-grown seedlings was not available because the original source trees had been eradicated, DNA samples from seedlings with the typical phenotype were available for comparison. In all cases, the EST-SSR genotypes of

Table 3. Results of genotypic analyses of sour orange seedlings with the indicated phenotypic characterization using up to 24 expressed-sequence tag simple-sequence repeat (EST-SSR) loci

\begin{tabular}{|c|c|c|c|}
\hline Seedling & Appearance ${ }^{a}$ & Zygotic or nucellar ${ }^{\mathbf{b}}$ & No. of informative SSR markers ${ }^{c}$ \\
\hline \multicolumn{4}{|l|}{ Set 1} \\
\hline S384 & Typical & Nucellar & $\ldots$ \\
\hline S389 & Atypical & Zygotic & 3 \\
\hline S391 & Atypical & Zygotic & 2 \\
\hline S396 & Typical & Nucellar & $\ldots$ \\
\hline S398 & Typical & Nucellar & $\ldots$ \\
\hline S415 & Typical & Nucellar & $\ldots$ \\
\hline S417 & Atypical & Zygotic & 1 \\
\hline S433 & Atypical & Zygotic & 4 \\
\hline S439 & Typical & Nucellar & $\ldots$ \\
\hline S440 & Atypical & Zygotic & 3 \\
\hline S441 & Typical & Nucellar & $\ldots$ \\
\hline S443 & Typical & Nucellar & $\ldots$ \\
\hline S455 & Typical & Nucellar & $\ldots$ \\
\hline S1013 & Atypical & Zygotic & 6 \\
\hline \multicolumn{4}{|l|}{ Set 2} \\
\hline S389 & Atypical & Zygotic & 9 \\
\hline S391 & Atypical & Zygotic & 6 \\
\hline S393 & Atypical & Zygotic & 12 \\
\hline S396 & Typical & Nucellar & $\ldots$ \\
\hline S398 & Typical & Nucellar & $\ldots$ \\
\hline S414 & Atypical & Zygotic & 2 \\
\hline S415 & Typical & Nucellar & $\ldots$ \\
\hline S421 & Typical & Nucellar & $\ldots$ \\
\hline S422 & Typical & Nucellar & $\ldots$ \\
\hline S426 & Typical & Nucellar & $\ldots$ \\
\hline S427 & Typical & Nucellar & $\ldots$ \\
\hline S428 & Atypical & Zygotic & 5 \\
\hline S429 & Typical & Nucellar & $\ldots$ \\
\hline S433 & Atypical & Zygotic & 9 \\
\hline S439 & Typical & Nucellar & $\ldots$ \\
\hline S440 & Atypical & Zygotic & 5 \\
\hline S441 & Atypical & Zygotic & 4 \\
\hline S455 & Typical & Nucellar & $\ldots$ \\
\hline
\end{tabular}

${ }^{a}$ Seedlings with either typical or various atypical growth patterns as described in text. Samples were provided for heterozygosity testing as two sets of coded DNA samples. DNA from some seedlings was used for independent tests in both sets 1 and 2.

b Seedlings not confirmed as zygotics are very likely, but not certainly, nucellar seedlings. They revealed no loss of alleles or any unique alleles at the loci surveyed.

${ }^{\mathrm{c}}$ Eight EST-SSR loci (all heterozygous) were surveyed on the samples in set 1, and 24 (18 heterozygous) on those in set 2 . Informative markers are those that revealed allele losses and, thus, identified plants originating from zygotic embryos. sour orange seedlings with the atypical developmental phenotypes revealed their zygotic origin from self-fecundation and the result of sexual recombination to produce novel genotypes. Typical seedlings were apparently nucellar embryos because no genotypic differences were found among the various loci surveyed. Inbreeding depression, characterized by weak and unthrifty plant phenotypes, is a common observation when zygotic seedlings are found among seedling populations from normally nucellar embryo citrus types. Taken together with the negative PCR results on even these unusual-appearing plants, we conclude that the atypical phenotypes are completely explained by virtue of their zygotic origins.

Other workers have carried out similar experiments and have published abstracts with results that differ from ours. Zhou et al. (42) reported the presence of ' $\mathrm{Ca}$. L. asiaticus' in seed produced by experimentally inoculated periwinkle (Catharanthus roseus) and dodder plants (Cuscuta pentagona). The putative pathogen could be limited to the seed coat, as reported for ' $\mathrm{Ca}$. L. asiaticus' in citrus (35). However, this group also reported "mild" symptoms of HLB in seedlings. The symptoms were reversed by fertilization, which would not be expected with HLB. Also, the populations of ' $\mathrm{Ca}$. L. asiaticus' as estimated by qPCR did not increase in these plants. These authors postulated an "undescribed component" required for HLB that was not transmitted through seed (42). Benyon et al. (2) reported transmission of ' $\mathrm{Ca}$. L. asiaticus' through citrus seed but without "typical HLB." The population of the putative pathogen remained at very low levels in the seedlings, even after 3 years. It is impossible to evaluate these preliminary data critically and we await future complete descriptions of their experiments and data.

In conclusion, we have observed 723 seedlings grown from seed obtained from symptomatic fruit borne on trees that were symptomatic for HLB and which were confirmed to be positive for ' $\mathrm{Ca}$. L. asiaticus' by either standard PCR or qPCR tests. None of these seedlings displayed yellow shoots, blotchy mottle, dieback, or other symptoms typical of HLB. None of the qPCR tests was positive for ' $\mathrm{Ca}$. L. asiaticus' after 40 cycles of amplification. Thus, the earlier report of transmission of ' $\mathrm{Ca}$. L. asiaticus' through citrus seed (39) is not confirmed, and we can provide no evidence that transmission of ' $\mathrm{Ca}$. L. asiaticus' through citrus seed occurs, at least within the cultivars tested, even when seed from severely symptomatic fruit is sown. Our result is limited by the number of seedlings planted, grown, and tested. Testing of a larger number of seedlings could still detect transmission of the pathogen and, while this manuscript was in preparation, the results of such a study have ap- 
peared. Albrecht and Bowman (1) reported on the testing of much larger numbers of rootstock seedlings grown from seed collected from HLB-exposed and ' $\mathrm{Ca}$. L. asiaticus'-infected rootstock seed source trees in Florida. Most of the seedlings were evaluated for symptoms only, but 686 seedlings were tested by standard PCR over a period of 4 to 7 months. As in our study, symptoms of HLB were not observed in any of the seedlings. However, these authors reported weakly positive PCR results from two of these seedlings (1). The PCR-positive seedlings were not positive in subsequent tests. Regulatory officials and nurserymen may wish to take the results of these studies into account when planning citrus protection and production activities.

\section{ACKNOWLEDGMENTS}

We thank the Florida Citrus Production Research Advisory Council, Peter McClure chairman, for grant support; and C. Paul, J. Cabrera-Woscek, and R. Clarke for skillful technical assistance.

\section{LITERATURE CITED}

1. Albrecht, U., and Bowman, K. D. 2009. 'Candidatus Liberibacter asiaticus' and huanglongbing effects on citrus seeds and seedlings. HortScience 44:1-7.

2. Benyon, L., Zhou, L., McCollum, G., Powell, C., Hall, D., Irey, M., and Gottwald, T. 2009. Seed transmission of 'Candidatus Liberibacter asiaticus in citrus without typical huanglongbing. (Abstr.) Phytopathology 99:S11.

3. Bové, J. M. 1984. Wall-less prokaryotes of plants. Annu. Rev. Phytopathol. 22:361-396.

4. Bové, J. M. 2006. Huanglongbing: a destructive, newly-emerging, century old disease of citrus. J. Plant Pathol. 88:7-37.

5. Chang, C. J., Garnier, M., Zreik, L., Rossetti, V., and Bové, J. M. 1993. Culture and serological detection of the xylem-limited bacterium causing citrus variegated chlorosis and its identification as a strain of Xylella fastidiosa. Curr. Microbiol. 27:137-142.

6. Chen, C., Bowman, K. D., Choi, Y. A., Dang, P. M., Rao, M. N., Huang, S., Soneji, J. R., McCollum T. G., Gmitter, F. G., Jr. 2008. ESTSSR genetic maps for Citrus sinensis and Poncirus trifoliata. Tree Genet. Genomes 4:1-10.

7. Chen, C., Zhou, P., Choi, Y. A., Huang, S., and Gmitter, F. G., Jr. 2006. Mining and characterizing microsatellites from citrus ESTs. Theor. Appl. Genet. 112:1248-1257.

8. Chen, J., Pu, X., Deng, X., Liu, S., Li, H., and Civerolo, E. 2009. A phytoplasma related to 'Candidatus Phytoplasma asteri' detected in citrus showing huanglongbing (yellow shoot disease) symptoms in Guangdong, P.R. China. Phytopathology 99:236-242.

9. da Graça, J., and Korsten, L. 2004. Citrus huanglongbing: review, present status and future strategies. Pages 229-245 in: Diseases of Fruits and Vegetables, Vol. I. S. A. M. V. Naqvi, ed. Kluwer, Dordrecht, The Netherlands.

10. Dagulo, L., Danyluk, M. D., Spann, T., Filomena Valim, M., Goodrich, R., Sims, C., and Rouseff, R. 2009. Chemical characterization of orange juice from trees infected with citrus greening (huanglongbing). J. Food Sci. 75:C199-C207.

11. Davis, M. J., Mondal, S. N., Chen, H., Rogers, M. E., and Brlansky, R. H. 2008. Cocultivation of 'Candidatus Liberibacter asiaticus' with actinobacteria from citrus with huanglongbing. Plant Dis. 92:1547-1550.

12. Duan, Y., Zhou, L., Hall, D. G., Li, W., Dod- dapaneni, H., Lin, H., Liu, L., Vahling, C. M., Gabriel, D. W., Williams, K. P., Dickerman, A., Sun, Y., and Gottwald, T. 2009. Complete genome sequence of citrus huanglongbing bacterium, 'Candidatus Liberibacter asiaticus' obtained through metagenomics. Mol. PlantMicrobe Interact. 22:1011-1020.

13. Florida Department of Agriculture and Consumer Services. 2005. U.S. Department of Agriculture and Florida Department of Agriculture confirm detection of citrus greening. Department Press Release 30.

14. Garnett, H. M. 1984. Isolation of the greening organism. Pages 4-6 in: Symp. Citrus Greening. Nelspruit, South Africa.

15. Garnier, M., and Bové, J. 1983. Transmission of the organism associated with citrus greening disease from sweet orange to periwinkle by dodder. Phytopathology 73:1358-1363.

16. Ghosh, S. K., Raychaudhuri, S. P., Varma, A., and Nariani, T. K. 1971. Isolation and culture of mycoplasma associated with citrus greening disease. Curr. Sci. 40:299-300.

17. Gottwald, T. R., da Graça, J. V., and Bassanezi, R. B. 2007. Citrus huanglongbing: the pathogen and its impact. Plant Health Progress doi:10.1094/PHP-2007-0906-01-RV.

18. Hansen, A. K., Trumble, J. T., Stouthamer, R., and Paine, T. D. 2008. New huanglongbing (HLB) Candidatus species, 'Ca. Liberibacter psyllaurus,' found to infect tomato and potato is vectored by the psyllid Bactericera cockerelli (Sulc). Appl. Environ. Microbiol. 75:5862-5865.

19. Hartung, J. S., Beretta, J., Brlansky, R. H., Spisso, J., and Lee, R. F. 1994. Citrus variegated chlorosis bacterium: axenic culture, pathogenicity, and serological relationships with other strains of Xylella fastidiosa. Phytopathology 84:591-597.

20. Husain, M. A., and Nath, D. N. 1927. The citrus psylla (Diaphorina citri, Kuw.) [Psyllidae: Homoptera]. Mem. Dep. Agric. India Entomol. Ser. Vol. 10:5-27.

21. Jagoueix, S., Bové, J.-M., and Garnier, M. 1994. The phloem-limited bacterium of greening disease of citrus is a member of the alpha subdivision of the Proteobacteria. Int. J. Syst. Bacteriol. 44:379-386.

22. Jagoueix, S., Bové, J. M., and Garnier, M. 1996. PCR detection of the two 'Candidatus Liberibacter species' associated with greening disease of citrus. Mol. Cell. Probes 10:43-50.

23. Li, R., Mock, R., Huang, Q. Abad, J., Hartung, J., and Kinard, G. 2008. A reliable and inexpensive method of nucleic acid extraction for the PCR-based detection of diverse plant pathogens. J. Virol. Methods doi:10.1016/j. jviromet.2008.09.008.

24. Li, W., Hartung, J. S., and Levy, L. E. 2006. Quantitative real time PCR for detection and identification of 'Candidatus' Liberibacter species' associated with citrus huanglongbing. J. Microbiol. Methods 66:104-115.

25. Li, W., Hartung, J. S., and Levy, L. E. 2007. Evaluation of DNA amplification methods for improved detection of 'Candidatus Liberibacter species' associated with citrus huanglongbing. Plant Dis. 91:51-58.

26. Li, W., Levy, L., and Hartung, J. S. 2009. Quantitative distribution of 'Candidatus Liberibacter asiaticus' in citrus plants with citrus huanglongbing. Phytopathology 99:139144.

27. Li, W. B., Pria, W. D., Jr., Lacava, P. M., Qin, X., and Hartung, J. S. 2003. Presence of $X y$ lella fastidiosa in sweet orange fruit and seeds and its transmission to seedlings. Phytopathology 93:953-958.

28. Liefting, L. W., Sutherland, P. W., Ward, L. I., Paice, K. L., Weir, B. S., and Clover, G. R. G. 2009. A new 'Candidatus Liberibacter species' associated with diseases in solanaceous crops. Plant Dis. 93:208-214.
29. Liefting, L. W., Weir, B. S., Pennycook, S. R. and Clover, G. R. G. 2009. 'Candidatus Liberibacter solanacearum', associated with plants in the Solanaceae. Int. J. Syst. Evol. Microbiol. 59:2274-2276.

30. Lin, K. H. 1956. Yellow shoot of citrus. Symptomatology. Investigations in the cause of huanglongbing. Natural transmission and spread. General conclusions. Acta Phytopathol. Sin. 2:1-42.

31. Planet, P., Jagoueix, S., Bové, J. M., and Garnier, M. 1995. Detection and characterization of the African citrus greening Liberibacter by amplification, cloning, and sequencing of the rplKAJL-rpoBC operon. Curr. Microbiol. 30:137-141.

32. Schneider, H. 1968. The anatomy of citrus. Pages 1-85 in The Citrus Industry, vol. 2. W Reuther, W., Batchelor, L. D., and Webber, H. J. eds. University of California, Berkeley.

33. Sechler, A., Schuenzel, E. L., Cooke, P., Donnua, S., Thaveechai, N., Postnikova, E., Stone A. L., Schneider, W. L., Damsteegt, V. D., and Schaad, N.W. 2009. Cultivation of 'Candidatus Liberibacter asiaticus', 'Ca. L. africanus', and ' $\mathrm{Ca}$. L. americanus' associated with huanglongbing. Phytopathology 99:480-486.

34. Secor, G. A., Rivera, V.V., Abad, J. A., Lee, I.M., Clover, G. R. G., Liefting, L.W., Li, X., and DeBoer, S. H., 2009. Association of 'Candidatus Liberibacter solanacearum' with zebra chip disease of potato established by graft and psyllid transmission, electron microscopy, and PCR. Plant Dis. 93:574-583.

35. Tateneni, S., Shankar Sagaram, U., Gowda, S., Robertson, C. J., Dawson, W. O., Iwanami, T., and Wang, N. 2008. In planta distribution of 'Candidatus Liberibacter asiaticus' as revealed by polymerase chain reaction (PCR) and realtime PCR. Phytopathology 98:592-599.

36. Teixeira, D. C., Danet, J. L., Eveillard, S., Martins, E. C., Jesus, W. C., Jr., Yamamoto, P. T., Lopes, S. A., Bassanezi, R. B., Ayres, A. J., Saillard, C., and Bové, J. M. 2005. Citrus huanglongbing in Sao Paulo state, Brazil: PCR detection of the 'Candidatus Liberibacter species' associated with the disease. Mol. Cell. Probes 19:173-179.

37. Teixeira, D. C., Saillard, C., Eveillard, S. Danet, J. L., Ayres, A. J., and Bové, J. 2005 'Candidatus Liberibacter americanus', associated with citrus huanglongbing (greening disease) in Sao Paulo State, Brazil. Int. J. Syst. Evol. Biol. 55:1857-1862.

38. Teixeira, D. C., Wulff, N. A., Martins, E. C., Kitajima, E. W., Bassanezi, R., Ayres, A. J., Eveillard, S., Saillard, C., and Bové, J. M. 2008. A phytoplasma closely related to the pigeon pea witches'-broom phytoplasma (16Sr IX) is associated with citrus huanglongbing symptoms in the state of São Paulo, Brazil. Phytopathology 98:977-984.

39. Tirtawidjaja, S. 1981. Insect, dodder and seed transmissions of citrus vein phloem degeneration (CVPD). Proc. Int. Soc. Citricult. 1:469471.

40. Tyler, H. L., Roesch, L. F. W., Gowda, S., Dawson, W. O., and Triplett, E. W. 2009. Confirmation of the sequence of 'Candidatus Liberibacter asiaticus' and assessment of microbial diversity in huanglongbing-infected citrus phloem using a metagenomic approach Mol. Plant-Microbe Interact. 22:1624-1634.

41. van den Bert, M. A., Van Vuuren, S. P., and Deacon, V. E. 1992. Studies on greening disease transmission by the citrus Psylla, Trioza erytreae (Hemiptera: Triozidae). Israel J. Entomol. 25-26:51-56.

42. Zhou, L., Duan, Y., Gabriel, D., and Gottwald, T. R. 2008. Seed transmission of 'Candidatus Liberibacter asiaticus' in periwinkle and dodder resulted in low bacterial titer and very mild disease in periwinkle. (Abstr.) Phytopathology 98:S181. 